\title{
ADOPTION AND DEVELOPMENT OF ALTERNATIVE FUEL VEHICLES IN TRINIDAD AND TOBAGO
}

\author{
Kohan Dolcy ${ }^{1}$ and Trevor Townsend ${ }^{2 *}$ \\ ${ }^{1,2}$ Faculty of Engineering, The University of the West Indies, Trinidad and Tobago \\ ${ }^{1}$ Email: kohan.dolcy@sta.uwi.edu \\ ${ }^{2}$ Email: Trevor.Townsend@ sta.uwi.edu* (Corresponding author)
}

\begin{abstract}
The transport sector has been identified as one of the highest contributors to greenhouse gas emissions in Trinidad and Tobago owing to the increase in the number of vehicles and the inherent traffic congestion. The vehicles are mainly fuelled by conventional fuels with relatively few being alternative fuel vehicles (AFVs), primarily in the form of compressed natural gas (CNG) vehicles. This research explores the current situation with the development and adoption of AFV technology in Trinidad \& Tobago. In Trinidad, the natural gas supply is already well-established, refuelling stations are in operation and up to 18 original equipment manufacturer CNG vehicles are available on the market, supplemented by the option of vehicle conversion. The opposite is true for electric vehicles, with only one recognized dealer offering electric vehicles and public charging stations, and only one related market incentive in effect. Despite the number of initiatives geared toward CNG development, the 2018 vehicle conversion targets have not been realized and it would require a very aggressive approach to achieve those figures by 2020. The authors have identified the key impediments to successful attainment of the targets. They note that few of the ongoing fiscal incentives, measures or pilot projects by the government ministries that are associated with renewable energies are directly linked to the transportation sector. Additionally, since measures of effectiveness for sustainability are not being monitored, the country cannot adequately determine its progress towards sustainability. The authors propose measures towards achieving sustainable development in transportation and to overcome the constraints of data availability, perceived barriers to AFV adoption and the notion of affordability over sustainability.
\end{abstract}

Keywords: Alternative fuel vehicle, Compressed natural gas, Sustainability, Transportation, Trinidad and Tobago.

https://doi.org/10.47412/TMDM6163

\section{Introduction}

The transportation system of Trinidad and Tobago is a unique one when compared with other small states in the Caribbean. Although small island developing states (SIDS) are characterized by scarce resources, Trinidad and Tobago has the benefit of more abundant and diversified resources in the form of oil and natural gas reserves. Notwithstanding, alternative fuel vehicles are present but not prevalent in the transportation system. The majority of the AFVs are powered by CNG, which, 
like gasoline, is a fossil fuel and a non-renewable source of energy. Raghoo, et al. [1] recommend that $\mathrm{CNG}$ be developed alongside electricity from renewable energy resources to improve the energy security of small islands. However, the more viable fuel options for Trinidad and Tobago, CNG and electricity, have technical, social and economic drawbacks that challenge their widespread application. While cost and the limited range of AFVs have been identified as major concerns for both users and implementing agencies, several non-cost barriers also exist [2, 3, 4].

\section{The Local Road Transportation Discourse}

The Trinidad and Tobago transportation system is comparably larger and supposedly more advanced than that of the remaining SIDS in the region. The citizens of Trinidad and Tobago benefit from relatively cheap fuel options, an efficient new and used vehicle market, and an extensive road network of arterials and highways, including a dedicated bus route along the EastWest Corridor. The transport sector has however been identified as one of the highest contributors to the total GHG emissions in Trinidad and Tobago [5, 6] and the transportation system is fraught with issues that affect its effectiveness and efficiency. Figure 11 shows a snapshot of the twinisland which gives an overview of the land use, economic activity, and communication links.

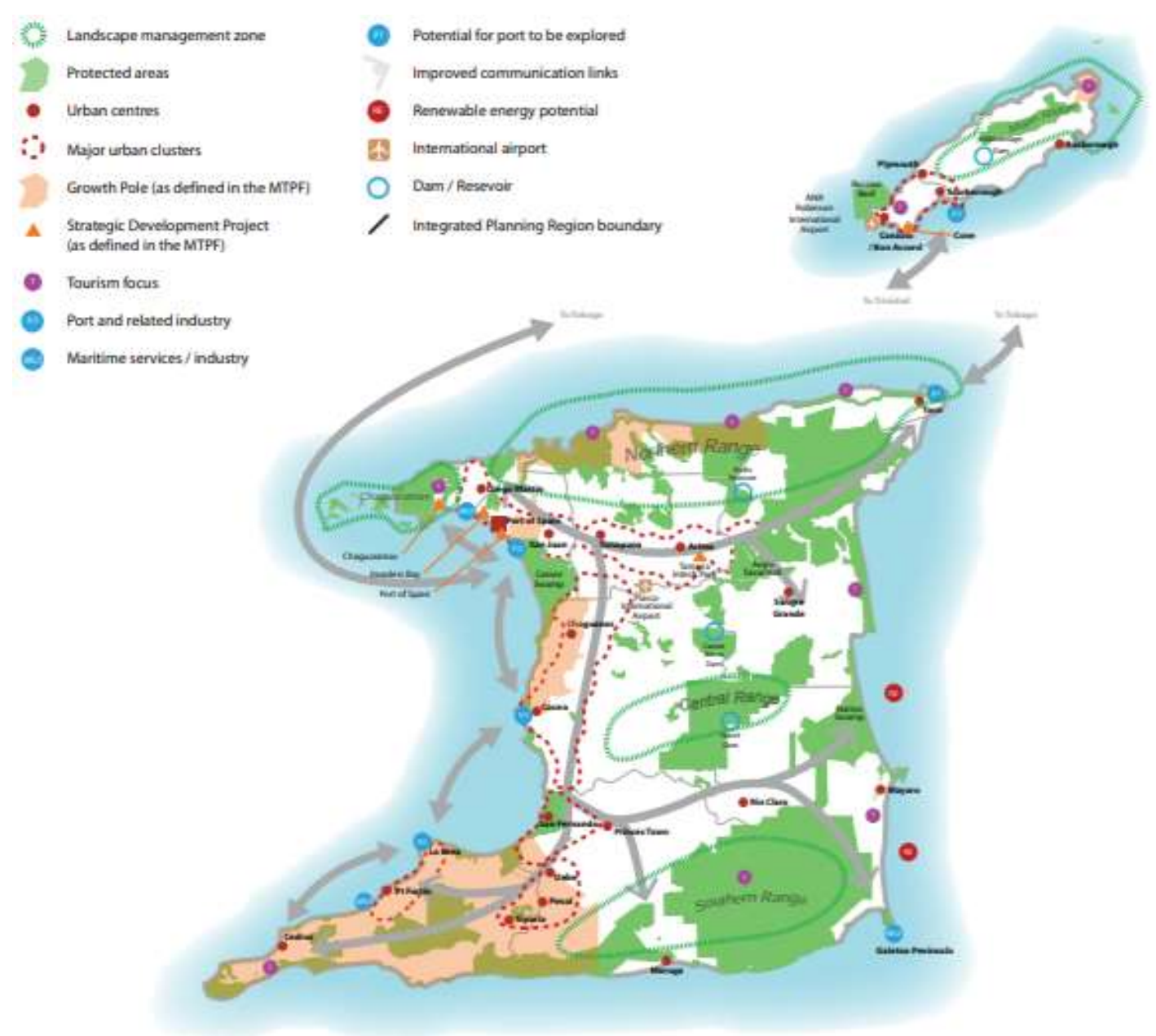

Figure 11. Trinidad and Tobago land use, economic activity and communication links [7] 


\subsection{The Issues}

\subsubsection{Fuel Prices}

The country is currently one of the cheapest fuel retailers in Latin America and the Caribbean, preceded by Venezuela, Panama and SIDS like Puerto Rico and Haiti. In Trinidad and Tobago, heavily subsidized lower grade fuels coupled with relatively cheap imported vehicles, has resulted in affordable car ownership and little financial incentive to use alternative modes [8]. Both conventional and alternative fuels are commercially available in Trinidad and Tobago in the form of gasoline (super and premium grades), diesel, $\mathrm{CNG}$ and electricity. The retail prices of the conventional fuels have been increased by factors of 1.84, 1.92 and 2.27 respectively in the past 10 years while the price of CNG and electricity have remained unchanged [9]. Notwithstanding, the Ministry of Energy and Energy Industries (MEEI) has reported a decline in the volume of natural gas sold through the service station network from 2010 to 2015 [10].

\subsubsection{Availability of Alternative Fuels}

$\mathrm{CNG}$ is a cleaner fuel and generates fewer emissions than conventional fuels [11], making it an attractive solution for reduced pollutants generated through transportation. However, natural gas vehicles (NGVs) from conversions emit much more pollutants and use more fuel than original equipment manufacturer (OEM) NGVs [12]. Electric vehicles (EVs) also claim to be carbon neutral, but the cleanness of the electricity depends on the source [13, 14]. In Trinidad and Tobago, $99 \%$ of the electricity is generated primarily from natural gas [15] and therefore the difference in the quality of emissions from the two types of AFVs being considered is ultimately dependent on the efficiency of the fuel supply infrastructure and the vehicles.

In Trinidad, the natural gas supply is already well-established, refuelling stations are in operation and up to 18 OEM CNG vehicles are available on the market, supplemented by the option of certified vehicle conversion. The typical refuelling station in Trinidad and Tobago currently offers at least one grade of gasoline, along with diesel, and only 11 of the 140 refuelling stations currently open for public use in Trinidad (Tobago excluded) offer CNG as a fuel option. The opposite is true for electric vehicles, with only one recognized new vehicle dealer offering EVs and only five public charging stations in existence, four of which are at that company's locations.

\subsubsection{Vehicle Population}

Espinasa and Humpert [16] estimate that "in 2010, there were 518,831 motor vehicles on the road and in total more than one million vehicles have been registered. Over the last decade alone, more than 250,000 cars have been added to the network and the per capita ownership of motor vehicles is very high with a ratio of 2.5 people for each car", while the US and the UK report a ratio of 2 $[17,18]$. The increase in the number of vehicles over the years has been reflected by an increase in energy consumption by the transportation sector [9] and is evident in the daily traffic congestion that plagues the roadways.

Data from the Ministry of Works and Transport confirms the significant growth in the vehicle population, recording a total number of 876,202 registered vehicles in 2017, 86 percent of which are classified as private vehicles. Townsend [19] reports that in Trinidad and Tobago, "95 percent of public transportation was provided by approximately 13,000 privately owned vehicles" and the 
Association of Maxi Taxis of Trinidad and Tobago estimates that the maxi-taxis serve approximately $75 \%$ of the travelling population with over 5000 vehicles. This vehicle population consists of vehicles fuelled by gasoline, diesel, $\mathrm{CNG}$, and electricity, some of which are hybrids and run on a combination of either of the fuel types.

\subsubsection{Accessibility of AFVs}

Table 26 gives an overview of the public transportation system, highlighting the characteristics and scope of each transportation mode. The four public transportation modes, namely bus, maxitaxi, taxis and private cars (locally known as ' $\mathrm{PH}$ '), each contain a representative quota of AFVs, primarily in the form of $\mathrm{CNG}$ vehicles. Each of the four modes have different ownership and operating arrangements, but cover the same geographical areas and afford most citizens, regardless of demographics, the convenience of public transportation. Public transportation in the country has nonetheless been described as poorly connected to residential communities, unmanaged, unscheduled, unreliable and confined to two main corridors, bordering on chaos in vehicles mobility and accessibility [19, 20,21].

The PTSC operates a bus service with a fleet of 315 [22], a decrease from 548 in 2014 [21] and has the advantage of transporting significantly more persons per trip than other transportation modes, benefitting from a 25 passenger seating capacity restriction specified for maxi-taxis [23]. Despite the evidence presented and the acknowledgement of this imbalance in passenger share by the review committee for amendment of the National Internal Transportation Policy (NITP) from as early as 1996, there has been no de-regularization of nor an increase in the vehicle seating capacity for maxi-taxis.

Table 26. Overview of the public transportation system in Trinidad and Tobago

\begin{tabular}{|c|c|c|c|c|c|}
\hline $\begin{array}{l}\text { Public } \\
\text { Transport } \\
\text { Entity }\end{array}$ & $\begin{array}{l}\text { Mode of } \\
\text { Transport } \\
\text { (capacity) }\end{array}$ & $\begin{array}{l}\text { No. of } \\
\text { Vehicl } \\
\text { es }\end{array}$ & 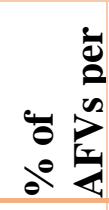 & $\begin{array}{l}\text { Estimated } \\
\text { Annual } \\
\text { Ridership }\end{array}$ & Characteristics \\
\hline PTSC & $\begin{array}{l}\text { Bus }(33-50 \\
\text { seats) } \\
\text { ELDAMO (8 } \\
\text { seats }+3 \\
\text { wheelchairs) }\end{array}$ & $\begin{array}{l}315 \\
(24)\end{array}$ & $\sim 20$ & $\begin{array}{l}12.6 \text { million } \\
(2010) \\
7.6 \text { million } \\
(2014)\end{array}$ & $\begin{array}{l}\text { State-owned; no fare increase } \\
\text { since 1990; express services; } \\
\text { subsidized fares; scheduled } \\
\text { services ranging from } 30 \\
\text { mins to three times a day but } \\
\text { not reliable; PBR access. }\end{array}$ \\
\hline \multirow[t]{2}{*}{$\begin{array}{l}\text { AMTTT, } \\
\text { AMTSTC } \\
\text { PSTATT, } \\
\text { Other }\end{array}$} & \multirow[t]{2}{*}{$\begin{array}{l}\text { Maxi taxis - } \\
\text { small and large } \\
(12-25 \text { seats })\end{array}$} & \multirow[t]{2}{*}{$5000+$} & \multirow[t]{2}{*}{$\sim 2$} & $\begin{array}{l}70 \%-80 \% \text { of } \\
\text { public } \\
\text { transport trips } \\
{[24]}\end{array}$ & \multirow[t]{2}{*}{$\begin{array}{l}\text { Frequent stops; reliable; PBR } \\
\text { access but some restricted to } \\
\text { the EMR; privately owned. } \\
\text { AMTSTC and PSTATT cater } \\
\text { to students under specific } \\
\text { agreements. }\end{array}$} \\
\hline & & & & \multirow{2}{*}{$\begin{array}{l}275 \text { million } \\
\text { pass. trips }\end{array}$} & \\
\hline $\begin{array}{l}\text { Taxis } \\
\text { (H plates) }\end{array}$ & $\begin{array}{l}\text { Route (Shared) } \\
\text { Taxis }\end{array}$ & $\begin{array}{l}13000 \\
+\end{array}$ & $\sim 5$ & & $\begin{array}{l}\text { Generally operate from taxi } \\
\text { stands around cities and }\end{array}$ \\
\hline
\end{tabular}


(5-7 seats)

Private Taxis $(\mathrm{H})$

(5-7 seats)

\begin{tabular}{l|l|l} 
TTRS, & Private Cars - & unknown \\
PinkCab, & ridesharing & \\
DROP, & $(5-7$ seats $)$ & \\
etc. & &
\end{tabular}

towns; reliability varies with the route; off route transfers cost more.

Operate from air and sea ports; private tours

Custom location requests includes airport transfers and shopping trips or other errands.

Source: Developed by [9] from multiple local sources, including [19, 21, 24]

\subsection{Proposed Solutions}

While there has been much discussion and debate on the problems caused by the use of conventional fuels in the transportation system, a plethora of advice has been offered by local stakeholders and international agencies. Furlonge [25] summarized the proposed policy measures and associated improvement projects for the consideration of the government of the Republic of Trinidad and Tobago (GORTT) [26] and emphasised the importance of their integration and prioritisation in the country's short- and long-term traffic and transportation plans. Townsend [19] also highlighted the requirements for sustainable transportation development. Other suggestions for an improved transportation system, not currently in effect include: land use growth management [27]; annual vehicle permit tax on households with multiple vehicles, fuel subsidy directed at public transport and goods vehicles, on-street parking charges, increased parking charges in urban areas [28]; public sensitisation through electric car shows, free urban area parking and ferry transport for electric [green] vehicles, installation of charging ports at frequently visited locations, increased private sector involvement and sustainable funding for the services in the form of user targeted and not producer targeted subsidies [19].

Townsend [29] highlights that the major constraints to sustainability progress are: "i) lack of desire; ii) higher priority on affordability than sustainability, and iii) short-term rather than longterm priorities". Dolcy [9] also determined that some of the identified barriers to AFV adoption are either not applicable to Trinidad and Tobago or been overcome by the policy implementations and other AFV developments taking effect from 2014. However, since the measures of effectiveness for sustainability are not being closely monitored, [9] impression that the country cannot adequately determine its progress towards sustainability. Dolcy [9] consequently proposes that i) renewable energy and energy efficiency in the use of fossil fuels be applied in transportation as both remedial and long-term measures towards achieving the sustainable development goals; ii) a monitoring, reporting and verification (MRV) system be implemented for the sustainability of the transportation system and iii) a more professional approach be employed in the management of the local transportation system. 


\section{AFV Oriented Policy}

In 2015, the GoRTT set a national target to achieve 10 percent of renewable energy generation by 2021. In addition, the intended nationally determined contribution (NDC) is to achieve a 15 percent (103 million $\mathrm{MtCO}_{2} \mathrm{e}$ ) reduction in overall emissions from the business as usual (BAU) case by 2030, in three sectors namely power generation, transportation and industrial [6, 30]. "Trinidad and Tobago will commit to unconditionally reduce its public transportation emissions by 30 percent (compared to 2013 levels) or 1.7 million MtCO2e by 2030" [6]. Although both the renewable energy and emission reduction targets for Trinidad and Tobago are low in comparison with the other CARICOM countries who have lower populations and much less industrialization, these commitments still mark progress towards sustainability. The sequencing of the recent and intended AFV policy developments is summarized in Figure 12.

\begin{tabular}{|c|c|c|}
\hline & 2016: & $\begin{array}{l}\text { Restrictions on } \\
\text { waiver of }\end{array}$ \\
\hline \multirow{2}{*}{$\begin{array}{l}\text { 2015: } \\
\text { 1. National RE } \\
\text { target set; }\end{array}$} & $\begin{array}{l}\text { Waiver of import } \\
\text { duties - new and }\end{array}$ & import duty. \\
\hline & $\begin{array}{l}\text { used vehicles: } \\
\text { a. CNG: < } 4 \text { yrs }\end{array}$ & \\
\hline \multirow{4}{*}{$\begin{array}{l}\text { 2. NDC set; } \\
\text { 3. National } \\
\text { CNG Standard } \\
\text { developed. }\end{array}$} & plus component & \\
\hline & parts. & \\
\hline & $\begin{array}{l}\text { b. EV: < } 4 \text { yrs; } \\
<179 \mathrm{~kW} .\end{array}$ & \\
\hline & $\begin{array}{l}\text { c. Hybrid: < } 4 \\
\text { yrs; <1999 cc. }\end{array}$ & \\
\hline
\end{tabular}

\begin{tabular}{|c|c|c|}
\hline \multirow{5}{*}{$\begin{array}{l}\text { 2020: } \\
\text { Waiver of import } \\
\text { duties ceases on: }\end{array}$} & & \multirow{10}{*}{$\begin{array}{l}\text { 2030: } \\
15 \% \text { reduction in } \\
\text { overall emission } \\
\text { from BAU case } \\
\text { of } 2013 \text {. }\end{array}$} \\
\hline & 2021: & \\
\hline & & \\
\hline & achieved & \\
\hline & Import duties still & \\
\hline \multirow{2}{*}{$\begin{array}{l}\text { a. CNG: < } 4 \mathrm{yrs} \\
>1599 \mathrm{~kW}\end{array}$} & valid for: & \\
\hline & a. $\mathrm{CNG}:<4 \mathrm{yrs} ;<$ & \\
\hline \multirow{2}{*}{$\begin{array}{l}\text { b. EV: < } 4 \text { yrs; } \\
160 \mathrm{~kW}<\text { engine } \\
<179 \mathrm{~kW} \text {. }\end{array}$} & $1599 \mathrm{cc}$. & \\
\hline & $\begin{array}{l}\text { b. EV: }<4 \text { yrs; }< \\
159 \mathrm{~kW} .\end{array}$ & \\
\hline $\begin{array}{l}\text { c. Hybrid: < } 4 \\
\text { yrs; } 1600 \mathrm{cc}< \\
\text { engine < } 1999 \text { cc. }\end{array}$ & $\begin{array}{l}\text { c. Hybrid: }<4 \\
\text { yrs; }<1599 \text { cc. }\end{array}$ & \\
\hline
\end{tabular}

Figure 12. Timeline of AFV related policy interventions [9]

Notwithstanding the above target, intention and commitment, none of the ongoing fiscal incentives, measures or pilot projects by the MEEI and the Ministry of Public Utilities (MPU) that are associated with renewable energies are directly linked to the transportation sector, but rather with basic electrical needs for residential, commercial, recreational and institutional entities. The Queen's Park Savannah Renewable Energy Project proposed under the International Renewable Energy Agency (IRENA) Grant will be the first pilot project that incorporates EV charging ports into its ambit, thereby catering to the transport sector. Upcoming modifications to the country's legislation will have an indirect impact on the transport sector by providing a cheaper, greener and more efficient alternative to electricity generation, reducing the limitations to the widespread use of EVs and facilitating more choice options for the end user.

\section{AFV Adoption and Development}

The NGC CNG was incorporated to accelerate the use of CNG as a major transportation fuel. The company has embarked on several initiatives as part of the CNG Expansion Program, including: 
a. Waiver of value-added tax and motor vehicle tax on OEM CNG and Electric Vehicles;

b. Tax credits of up to $25 \%$ of the cost of conversions (gasoline/diesel to $\mathrm{CNG}$ ) for individuals;

c. Capital uplift of $130 \%$ for wear and tear on the cost of commercial fleets conversions;

d. Establishment and expansion of CNG filling stations;

e. Mobile CNG refuelling units commissioned to distribute CNG between Trinidad and Tobago;

f. New Maxi taxi grants for OEM purchases of small and large maxi taxis;

g. Free maxi-taxi and taxi conversions offered to maxi-taxis and taxis (gasoline models only);

h. Pre-loaded fuel cards issued as a fuel incentive to the ordinary members of the Private School Transport Association of Trinidad and Tobago (PSTATT);

i. Free private vehicle conversions to members of the public through a biweekly raffle draw;

j. Training program for CNG Engine Maintenance technicians in collaboration with the National Energy Skills Centre (NESC);

k. Development of a CNG Standard through the Trinidad and Tobago Bureau of Standards (TTBS).

According to the initial investment plan, 20 percent of the total vehicle population would be converted to CNG by year five, seeing a total of 100,000 NGVs in Trinidad and Tobago. Figure 13 shows the current status of CNG adoption alongside the 2015 targets, with projection scenarios for 2020. By mid-2019, only 5300 vehicles had been converted [9]. While these developments in CNG as an alternative fuel have been emerging and expanding, the advancement of electricity as an alternative fuel in Trinidad and Tobago is relatively slow. Of the nine initiatives under the CNG Expansion Program, only Item a is also applicable to select categories of hybrid and electric vehicles. Even the options available for purchase of new EV or electric hybrid are limited to one local dealership who reports that the hybrid is a lot more popular than the pure EV.

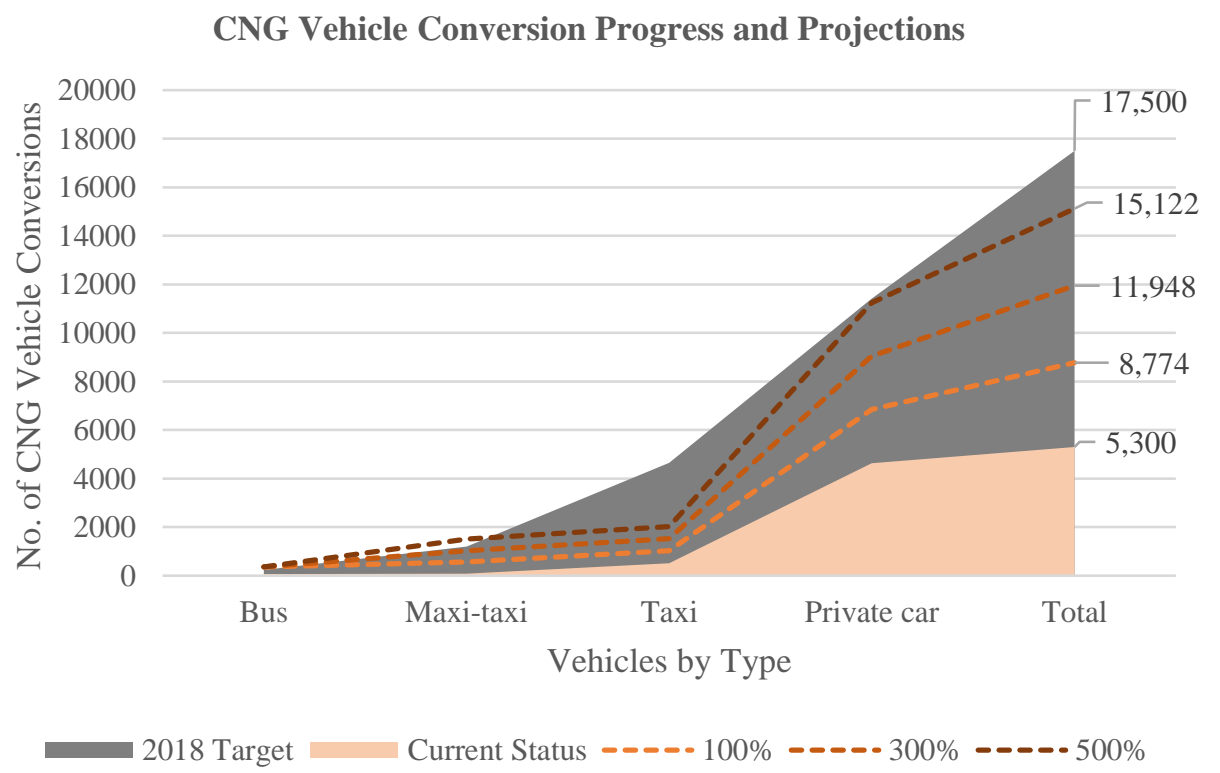

Figure 13. CNG development as at mid-2019 in relation to the NGC CNG 2018 target [9] 


\section{Inferences}

The following inferences have been gathered from the discussion on the current situation regarding AFVs in the Trinidad and Tobago transportation system:

i. Programs and policies have been established to promote the use of CNG as an alternative fuel geared toward mass transit in Trinidad and Tobago, but "there is currently no single body responsible for the organisation, coordination and regulation of the public transport sector" [24], nor the monitoring their effectiveness. Similarly, the performance of the stateowned PTSC, which operates the largest AFV fleet has not been adequately monitored nor evaluated [21].

ii. Some of the identified barriers to AFV adoption (e.g. driving range, filling time, safety, reduction in cargo space and loss of power) have been overcome in Trinidad and Tobago but are still perceived to exist. Elimination of these barriers will require a combination of increased education and awareness, behavioural change, policy and technological updates, along with continuous evaluation.

iii. Increasing the number of alternative fuel vehicles will merely increase the total vehicle population unless coupled with reduction measures such as early retirement of vehicles and stricter measures for roadworthiness. This also requires appropriate procedures and facilities for recycling and or disposal of the vehicles (and their parts) being deregistered and discarded.

\section{Achieving Sustainable Transport with AFVs}

The authors' observations suggest that sustainable transport can be achieved by making some minor and progressive adjustments in the transportation and interrelated systems. The recommendations discussed below are intended to address the identified barriers and constraints:

1. Data collection, research and development programs should be influenced by studentindustry partnerships to ensure that the research needs of the country are met while reducing the burden of resources required to obtain the necessary data for sustainability monitoring. For example, the Multiple Indicator Cluster Survey (MICS) utilized by the Central Statistics Office (CSO) can be used to capture information on household transportation expenditure, motorization values and the attitude of the population towards the AFVs.

2. Behavioural change is required to address the tendency of the stakeholders to see CNG and electric vehicles as competitors as opposed to focusing on an increased proportion of clean fuels in the energy mix. This demands a continuous and evolving awareness and education approach targeting all age ranges, income brackets, educational backgrounds, and disciplines.

3. Government entities and political leaders must be prepared to display the political will required to address the upsurge in the new technology, by setting the example as AFV trendsetters and allocating the necessary resources (manpower, equipment, and funding) to accommodate. Capacity building and institutional strengthening at all levels is required and should involve local specialists like Transportation Planners, Transportation Engineers, Land-Use Planners and Architects. 
4. High occupancy and clean vehicle priorities can encourage persons to play their part in contributing to the transportation system sustainability. While the authors do not recommend giving priority to clean vehicles on the Priority Bus Route (PBR), High Occupancy Vehicle (HOV) lanes assigned during peak hours on the various highways can also accommodate single occupancy vehicles that run on clean fuels. Limitations on intercity access should also see increased awareness and respect for clean fuel vehicle technologies and HOVs.

5. Further to the recommendations by [25] and other stakeholders to establish a transit authority, the NITP recommended that the agency responsible for the administration of privately supplied services be responsible for the administration of publicly supplied services as well. "By setting up public agencies to oversee particular sections of the transport industry, governments can influence the entire character and performance of the industry" [18]. The authors suggest that these recommendations be reconsidered and that a transit authority be established to ensure that adequate public transportation services are provided to all users, with the options of partial state ownership, wet leasing, subcontracting and franchising [31].

6. The authors advise that the winning proposal for the improvement of intracity transit must give priority to cleaner fuel vehicles or non-motorized modes of transport operating within the city, whether it is for shuttle services from a central hub or from park and ride facilities. Persons whose vehicles still run on conventional fuels can make their contribution to transportation system sustainability through these facilities on a regular basis.

7. "There are two main ways of increasing energy efficiency and achieving sustainable energy development - one is reducing the input costs of electricity through the use of more efficient equipment, thus also reducing fossil fuel consumption" [32]. This can be actively pursued on expiration of the PPAs in the next 10 years. In the interim, a demand-side management approach could raise awareness of the need to preserve the country's nonrenewable resources and thereby accelerate energy efficiency. T\&TEC would then be in an ideal position to perform a rate review that considers and makes appropriate adjustments for the incorporation of renewable energy onto the country's power grid.

8. "The other [way] is to generate electricity by substituting the traditional use of fossil fuels with renewable sources" [32]. "Wind energy is the preferred technology for power generation for supply to the national grid" [33] but [34, 35] have even been exploring the possibility of wave energy for SIDS. By incorporating these forms of renewable energy (RE) into the energy mix, Trinidad and Tobago is poised to further reduce the cost of producing electricity. Notwithstanding the PPAs that hinder immediate integration of RE on the islands, the authors propose a utility-scale solar project for the island of Tobago, whose electricity generation is carried out by T\&TEC and not an IPP. The island can be used as a pilot project to test the implementation of electricity as an alternative fuel and thereby serve as a model for other Caribbean SIDS.

\section{Conclusion}

The GoRTT has invested millions of dollars into the advancement of CNG as an alternative fuel to date but the uptake has not been as successful as anticipated. The major impediments to its adoption include reduced cargo space, perceived safety issues; insufficient infrastructure and highly subsidised conventional fuel prices. Although the efficiency of the country's electricity 
generation from natural gas has been praised, the use of natural gas as a fuel is currently more viable than electricity. As such, the use of electricity as an alternative fuel is even less prevalent despite the recognized benefits of incorporating renewable energy into the energy mix. AFVs can play a subtle yet effective role in improving the sustainability of the transportation system. The increased uptake of AFVs, however, requires that the underlying legislative, technical and social hindrances be addressed by improving public awareness and prioritizing both public transit and clean vehicle technologies. The above inferences and recommendations further highlight the need for more involvement of professionals in the management of the local transportation system.

\section{References}

[1] P. Raghoo, D. Surroop, and F. Wolf, "Natural gas to improve energy security in Small Island Developing States: A techno-economic analysis," Development Engineering, vol. 2, no. 2017, pp. 92-98, 2017.

[2] D. Browne, M. O'Mahony, and B. Caulfield, "How should barriers to alternative fuels and vehicles be classified and potential policies to promote innovative technologies be evaluated?," Journal of Cleaner Production, vol. 35, pp. 140-151, 2012.

[3] S. Shepherd, P. Bonsall, and G. Harrison, "Factors affecting future demand for electric vehicles: A model based study," Transport Policy, vol. 20, pp. 62-74, 2012.

[4] T. S. Stephens, "Non-Cost Barriers to Consumer Adoption of New Light-Duty Vehicle

Technologies," in "Transportation Energy Future Series," U.S. Department of Energy by

Argonne National Laboratory, Illinois, USDOE/GO-102013-3709, 2013, Available:

http://www.nrel.gov/docs/fy13osti/55639.pdf.

[5] (2015). Strategy for Reduction of Carbon Emissions in Trinidad and Tobago, 2040: Action plan for the mitigation of GHG emission in the electrical power generation, transport and industry sectors.

[6] (2015). Intended Nationally Determined Contribution (iNDC) Under the United Nations

Framework Convention Climate Change. Available:

https://www4.unfccc.int/sites/ndcstaging/PublishedDocuments/Trinidad\%20and\%20Tobago\%20

First/Trinidad\%20and\%20Tobago\%20Final\%20INDC.pdf.

[7] Trinidad and Tobago. MPSD (Ministry of Planning and Sustainable Development), "NSDS Core Strategy and Regional Guidance," in "National Spatial Development Strategy," MPSD, Port of Spain, Trinidad and Tobago, 2014.

[8] Globe Consultants International Ltd., "Surveying the Scene," in "National Spatial Development Strategy (NSDS) for Trinidad and Tobago " Ministry of Planning and Development, Port of Spain, 2013,

Available:

https://www.planning.gov.tt/OurTnTOurFuture/documents/Surveying the_Scene_web.pdf.

[9] K. Dolcy, "Alternative Fuel Vehicles for the Sustainability of the Transportation System - A Study of Trinidad and Tobago," Master of Science in Civil Engineering, Department of Civil and Environmental Engineering, The University of the West Indies, 2019.

[10] Trinidad and Tobago. MEEI (Ministry of Energy and Energy Industries). (n.d., Jan 1, 2020).

Trinidad and Tobago CNG Programme. Available: http://www.energy.gov.tt/ourbusiness/alternative-energy/report-on-the-trinidad-and-tobago-cng-programme/.

[11] U.S. Department of Energy (DOE). (n.d., November 3, 2018). Natural Gas Vehicles. Available: https://www.afdc.energy.gov/vehicles/natural_gas.html. 
[12] A. Janssen, S. F. Lienin, F. Gassmann, and A. Wokaun, "Model aided policy development for the market penetration of natural gas vehicles in Switzerland," Transportation Research Part A: Policy and Practice, vol. 40, no. 4, pp. 316-333, 2006.

[13] M. Yavuz, B. Oztaysi, S. C. Onar, and C. Kahraman, "Multi-criteria evaluation of alternativefuel vehicles via a hierarchical linguistic model," Expert Systems with Applications, vol. 42, pp. 2835-2848, 2014.

[14] S. J. Curran, R. M. Wagner, R. L. Graves, M. Keller, and J. B. Green, "Well-to-wheel analysis of direct and indirect use of natural gas in passenger vehicles," Energy, vol. 75, pp. 194-203, 2014. [15] N. C. Marzolf, F. C. Cañeque, J. Klein, and D. Loy, "A Unique Approach for Sustainable Energy in Trinidad and Tobago," Inter-American Development Bank (IADB), Washington, D.C. , 2015, Available: http://www.energy.gov.tt/wp-content/uploads/2016/08/A-Unique-Approachfor-Sustainable-Energy-in-Trinidad-and-Tobago.pdf.

[16] R. Espinasa and M. Humpert, "Energy Dossier: Trinidad and Tobago," Inter-American Development Bank (IADB), Technical Note, 2016, Accessed on: Feb 5, 2019.

[17] K. Agong, "Can 1.5 million Transportation Engineers be Wrong?," in ICE Seminar: Transportation Engineering: Addressing the Challenges, St. Augustine, Trinidad and Tobago, 2017, UK: Institution of Civil Engineers (ICE).

[18] J.-P. Rodrigue, The Geography of Transport Systems, 4th ed. New York: Routeledge, 2017, p. 440. [Online]. Available: https://transportgeography.org/?page_id=58. Accessed on April 18, 2019.

[19] T. Townsend, "Key Issues in the Future Development of our Transportation System," in Joint Consultative Council (JCC) Seminar on Housing, Building Construction \& Land Use in a Challenging Economy, Port of Spain, Trinidad and Tobago, 2016.

[20] R. Furlonge, Our Transportation System is in Crisis no. 39, March 15, 2007. Accessed on: March 6, 2019 Available:

http://www.lfsystemstt.com/assets/our_transportation_system_is_in_crisis_-_39.pdf.

[21] Trinidad and Tobago. AGD (Auditor General's Department), "Report of the Auditor General of the Republic of Trinidad and Tobago on a Special Audit of the Public Trasnport Service Corporation," AGD, Port of Spain, Trinidad and Tobago, 2016, Available:

http://www.auditorgeneral.gov.tt/sites/default/files/FINAL\%20-\%20PTSC\%20Report\%20-

$\% 2029$ th\%20June \%202016.pdf.

[22] (2018). Inquiry into the PTSC - Public Bus Service and Maintenance of Buses. Available:

http://www.ttparliament.org/documents/news/mr02968A.pdf.

[23] (2015). Maxi Taxi Act - Chapter 48:53.

[24] T. Townsend, "No Rapid Rail Does not mean No Mass Transit," in ICE Seminar:

Transportation Engineering: Addressing the Challenges, St. Augustine, Trinidad and Tobago, 2017, UK: Institution of Civil Engineers (ICE).

[25] R. Furlonge, Our Transportation System is in Crisis, no. 74, October 2009. Accessed on: April 14, 2019 Available:

http://www.lfsystemstt.com/assets/our_transportation_system_is_in_crisis_- 74.pdf.

[26] APDSL (All-Inclusive Project Development Services Ltd) and SoftCom Ltd, "A Framework for Implementation of National Transport Projects," National Infrastructure Development Company (NIDCO), Port of Spain, Trinidad and Tobago, 2010.

[27] R. Furlonge, Our Transportation System is in Crisis, no. 80, August 19, 2007. Accessed on: March 62019 Available:

http://www.lfsystemstt.com/assets/our_transportation_system_is_in_crisis_-_80.pdf. 
[28] R. Furlonge, Our Transportation System is in Crisis, no. 240, August 18, 2011. Accessed on: March 15, 2019 Available:

http://www.lfsystemstt.com/assets/our_transportation_system_is_in_crisis_-_240.pdf.

[29] T. Townsend, "Sustainable Transportation Development - A Trindad and Tobago Perspective," in United Nations CSD-19 IPM, 2011, p. 21.

[30] Trinidad and Tobago. MEEI (Ministry of Energy and Energy Industries), "Aide Memoire of Interview with H. Anyika (Senior Sustainable Energy Development Analyst) for the purpose of COEM 6018," Author, Ed., ed, 2019.

[31] (1996). National Internal Transportation Policy - Draft Final Report. Available: http://www.oas.org/en/sedi/dsd/Biodiversity/Sustainable_Cities/Sustainable_Communities/Event s/SC\%20Course\%20Trinidad\%202014/ModuleIII/NITP-96\%20Draft\%20Final.pdf.

[32] ECLAC, "Identification of mechanisms for financing of energy efficiency and renewable energy initiatives to increase investment in Saint Lucia," Port of Spain, Trinidad and Tobago, 2016, Available: https://repositorio.cepal.org/bitstream/handle/11362/40461/1/S1600827_en.pdf.

[33] Trinidad and Tobago. MEEA (Ministry of Energy and Energy Affairs), "Framework for Development of a Renewable Energy Policy for Trinidad and Tobago - A Report of the Renewable Energy Committee," Trinidad and Tobago, 2011.

[34] L. Henry et al., "Key factors around ocean-based power in the Caribbean Region, via Trinidad and Tobago," Renewable and Sustainable Energy Reviews, 2015.

[35] L. Henry, J. Bridge, K. Satahoo, H. Miller, B. Lougheide, and D. Garbutt, "Equator-Friendly Ocean Wave Energy Conversion," 2016. 